Original article

\title{
Value of schizophrenia treatment I: The patient journey
}

\author{
Pavel Mohr ${ }^{\mathrm{a}, \mathrm{b}, *}$, Silvana Galderisi ${ }^{\mathrm{c}}$, Patrice Boyer ${ }^{\mathrm{d}}$, Danuta Wasserman ${ }^{\mathrm{e}}$, Paul Arteel $^{\mathrm{f}}$, \\ Aagje Ieven $^{\mathrm{g}}$, Hilkka Karkkainen ${ }^{\mathrm{f}}$, Eulalia Pereira ${ }^{\mathrm{g}}$, Nick Guldemond ${ }^{\mathrm{h}}$, Petr Winkler ${ }^{\mathrm{a}, \mathrm{i}}$, \\ Wolfgang Gaebel ${ }^{\mathrm{j}}$
}

a National Institute of Mental Health, Klecany, Czech Republic

b 3rd Faculty of Medicine, Charles University Prague, Czech Republic

${ }^{\mathrm{c}}$ University of Campania Luigi Vanvitelli, Naples, Italy

d Université Paris Diderot - Paris 7, France

e National Centre for Suicide Research and Prevention of Mental Ill-Health (NASP), The Karolinska Institute, Stockholm, Sweden

${ }^{\mathrm{f}}$ Global Alliance of Mental Illness Advocacy Networks-Europe (GAMIAN Europe), Belgium

${ }^{g}$ European Federation of Associations of Families of People with Mental Illness (EUFAMI), Belgium

${ }^{\mathrm{h}}$ Institute of Health Policy \& Management, Erasmus University Rotterdam, Netherlands

i Institute of Psychiatry, Psychology and Neuroscience, King's College London, UK

${ }^{\mathrm{j}}$ LVR-Klinikum, Department of Psychiatry and Psychotherapy, Medical Faculty, Heinrich-Heine-University, Düsseldorf, Germany

\section{A R T I C L E I N F O}

Article history:

Received 19 April 2018

Received in revised form 18 June 2018

Accepted 25 June 2018

Available online 20 July 2018

\section{Keywords:}

Schizophrenia

Patient journey

Prevention

Treatment

Recovery

Mental health

\begin{abstract}
A B S T R A C T
Background: The aim of the European Brain Council project "The Value of Treatment" was to provide evidence-based, cost-effective policy recommendations for a patient-centered and sustainable coordinated care model for brain disorders. The first part of schizophrenia study examined the needs and gaps in the patients' care pathway.

Methods: Descriptive analysis was based on an inventory of needs and treatment opportunities, using focus group sessions, expert interviews, users' input, and literature review. Three patient pathways were selected: indicated prevention, duration of untreated psychosis, and relapse prevention.

Results: The analysis identified several critical barriers to optimal treatment. Available health care services often miss or delay detection of symptoms and diagnosis in at-risk individuals. There is a lack of illness awareness among patients, families, and the public; scarcity of information, training and education among primary care providers; stigmatizing beliefs. Early symptom recognition and timely intervention result in better outcome and prognosis; effective management leads to a functional recovery. In the current model of care, there is insufficient cooperation between health and social care providers, patients and families, inadequate utilization of pharmacological and psychosocial interventions, lacking patient monitoring, and low implementation of integrated community care. Conclusions: Early detection and early intervention programs, timely intervention, and relapse prevention are essential for effective management of schizophrenia. It requires a paradigm shift from symptom control, achieving and maintaining remission, to the emphasis on recovery. Since the current services are not able to accomplish this goal, changes in mental health policies are needed.
\end{abstract}

(c) 2018 Elsevier Masson SAS. All rights reserved.

\section{Introduction}

Schizophrenia is frequently a chronic and progressively disabling illness with negative impact on all aspect of a person's life [1]. It is a neurodevelopmental, heritable disorder with complex etiopathogenesis. The lifetime prevalence of

\footnotetext{
DOI of original article: http://dx.doi.org/10.1016/j.eurpsy.2018.06.008

* Corresponding author at: National Institute of Mental Health, Topolova 748, 250

67, Klecany, Czech Republic.

E-mail address: pavel.mohr@nudz.cz (P. Mohr).
}

schizophrenia is $0.8-1.5 \%$ of the population over 18 years; approximately 7-8 individuals out of 1000 will be diagnosed with schizophrenia in their lifetime [1,2].

The illness has a considerable negative impact not only on patients' health and well-being, but also on their immediate environment, posing a substantial burden for primary caregivers and families. The costs of the illness management are high both for individuals and society [3]. Mortality rates are approximately two to three times higher than those of the general population, due to both natural (attributable to a variety of somatic conditions) and unnatural causes (accidents, suicides), resulting in reduced life expectancy of 15-20 years [4]. Comorbid medical conditions, 
including consequences of life-style factors (e.g., smoking) and sub-optimal treatment of physical disorders, contribute to about $60 \%$ of the excess mortality; the lifetime rate of suicide risk in schizophrenia is approximately 5\% [5,6].

Symptoms of schizophrenia follow a typical path of development from a premorbid phase with detectable cognitive, motor or social deficits, through a prodromal phase characterized by brief, attenuated positive symptoms, and/or functional decline [5]. Alternatively, sudden onset of psychosis is also possible. Fully developed illness manifests itself as an acute psychotic phase with positive symptoms, resulting in a post-acute and subsequently a stable phase with negative and cognitive symptoms, subthreshold or residual positive symptoms, social and functional impairment [5].

The course of illness is highly variable, typically episodic, with exacerbations and remissions. Frequent relapses contribute to neurobiological impairment, further functional and social decline, and poor treatment response [7,8]. Relapse can be defined as a return of illness or symptoms after partial recovery; recurrence is a reappearance of illness after full remission or recovery. Exacerbation of illness might be triggered by drug withdrawal, non-specific psychosocial stressful situations (e.g., stress in professional environment, academic, personal life [relational distress]), or substance misuse. Schizophrenia outcome is a multidimensional concept that includes domains of psychopathology, social functioning, life-span and various aspects of quality of life, and societal impact [5]. Commonly cited predictors of more favorable outcome are acute onset of illness, good premorbid functioning, better cognitive function, absence of substance abuse, female gender, and a later age of onset.

More than $50 \%$ of schizophrenia patients suffer from intermittent but long-term psychiatric problems and approximately the same number of them has unfavorable outcome with chronic symptoms and disability, varying across countries [9-11]. It has been shown that even chronic illness can be effectively managed. Recovery and social reintegration through adequate treatment and care is possible in many cases, up to $20 \%$ of patients meet defined criteria of recovery [12]. However, data indicate that more than $50 \%$ of people with schizophrenia do not receive appropriate, timely, and adequate treatment. The World Health Organization assessed the accessibility of mental health services for schizophrenia patients and their utilization in 50 low- and middleincome countries [13]. The treatment gap was measured as the absolute difference between the prevalence of schizophrenia and the proportion of treated individuals. The median value for treatment coverage was $31 \%$; i.e., approximately two thirds (69\%) of the people with schizophrenia do not receive treatment. The treatment gap was larger in lower-income countries (89\%) than in lower-middle-income (69\%) and upper-middle-income countries (63\%) [13].

More than a decade ago, the European Brain Council (EBC) published a report "The Economic Cost of Brain Disorders in Europe" [14]. An updated report from 2010 estimated the total cost (direct healthcare and non-medical plus indirect) of psychotic disorders (including schizophrenia) in Europe at 93.9 billion Euros, 18,796 EUR per patient [15].

In 2016, EBC launched a new project, "The Value of Treatment" (VoT) that aimed to address equality gaps across the EU in early detection and intervention, diagnostics and treatments for brain (including mental) disorders. The ultimate goal was to provide evidence-based and cost-effective policy recommendations for the adoption and implementation of a more patient-centered and sustainable coordinated care model for brain disorders [16].

The VoT project focused on a number of neurological conditions and, as a single psychiatric disorder, schizophrenia. Working groups, composed by experts of the EBC member organizations, representatives of patient and family organizations, health policy and economic experts, and drug companies developed case studies for each disorder. The aim was to analyze the socioeconomic impact and health gains of selected evidence-based healthcare interventions in comparison with the cost of current care/nontreatment by carrying out combined cost-effectiveness evaluation of selected care pathway services and patients' journey and care modeling.

The patient journey is a description of how patients experience a disease or condition from their first awareness of symptoms through all stages of the illness. It represents an alternative view on mental illness, based on person's individual experience. Documenting the patient journey aims to identify key issues in the care for schizophrenia patients that need to be improved. A care pathway is a multidisciplinary management tool based on healthcare plan for a specific group of patients with a predictable clinical course, in which the different tasks by the professionals involved in the patient care are defined, optimized and sequenced [17]. The aim of a care pathway is to enhance the quality of care across the continuum by improving risk-adjusted patient outcomes, promoting patient safety, increasing patient satisfaction, and optimizing the use of resources.

In this paper, we present findings from the patients' care pathway analysis in schizophrenia. The objectives were (1) to examine the patients' needs along the patient journey; (2) to identify gaps and opportunities for improvements in the current care pathway; and (3) to propose general policy recommendations. The results of the second part, economic modeling assessing socioeconomic impact of specific clinical interventions targeted to close some of the gaps identified in the patient journey analysis (a case study from the Czech Republic), are presented in a separate paper [18].

\section{Methods}

The schizophrenia working group, led by WG, consisted of the members of the Board of the European Psychiatric Association (EPA), representatives of the Global Alliance of Mental Illness Advocacy Networks-Europe (GAMIAN-Europe), the European Federation of Associations of Families of People with Mental Illness (EUFAMI), economic and mental health policy experts of London School of Economics (LSE), Erasmus School of Health Policy \& Management, Erasmus University Rotterdam,

the Czech National Institute of Mental Health (NIMH), and the representatives of pharmaceutical industry. The study was sponsored by the EBC.

The care pathway of schizophrenia patients was analyzed in order to identify major barriers preventing patients from receiving timely and adequate treatment and care. The analysis served as the basis to develop consented recommendations on how to overcome them. Due to the heterogeneous course of illness with highly diverse individual trajectories, we focused on three highly relevant patient pathways (Fig. 1):

(1) Indicated prevention in individuals at risk of developing schizophrenia;

(2) Reducing the duration of untreated psychosis by timely intervention in patients with manifest, but not yet diagnosed schizophrenia;

(3) Relapse prevention in patients after a first episode of schizophrenia, and patients with episodic course of the illness.

The journey was based on an original inventory of needs and treatment opportunities, using focus group sessions, expert interviews, users' input, and literature review. The scope of questions covered all fields of interest: What services are currently 


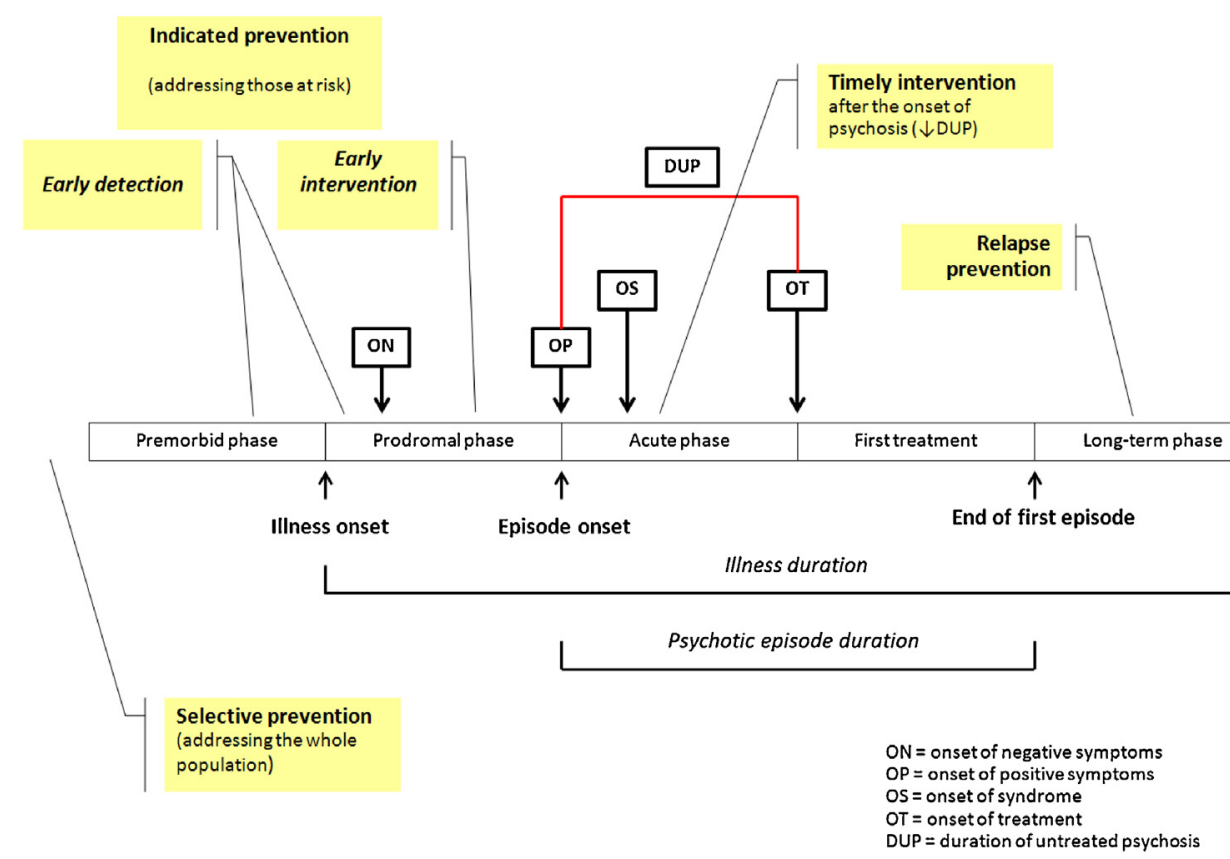

Fig. 1. Intervention strategies in the early course of schizophrenia (modified from [19]).

available? What are the unmet needs along the journey? What are the major challenges and barriers? What are the opportunities for improvement? What is the optimum model of care? What are the policy recommendations? The working group meetings, organized by the EBC, took place in Brussels between January 2016 and May 2017. Patient and family members' needs and their perspectives along the journey were collected through discussions with the patient and family organizations and from the conclusions of separately held meetings of the patients and family organizations (EUFAMI, GAMIAN). The results are based on the consensus of the experts and stakeholders.

\section{Results}

The paramount points concerning crucial illness stages, from at risk states through recovery, are listed in the Table 1.

Factors affecting patients' journey along the schizophrenia illness trajectory found in our care path analysis are summarized in the Table 2 .

\section{Discussion}

The value of treatment in psychiatry cannot be reduced to economic and financial aspects only. It is an asset for society, which can be measured as a value that an intervention provides to the patient and a "value for money" that the intervention provides to the payer. Thus, value comprises a combination of symptom reduction, improving quality of life, better social functioning, subjective well-being, physical health, guaranteed safety (e.g., suicide prevention programmes), and achieved cost-effectiveness. Long-term psychiatric treatment includes not only health care, but also requires resources and involvement of the social system. Comprehensive care should be provided and organised according to the patient's needs (person-oriented care). This means an easily accessible and a seamlessly integrated care network which is aimed at improving quality of life, while respecting patients' rights. Inevitable provisions of involuntary treatment or commitment in warranted cases must be regulated by the law, maintaining basic human rights. The network of care, where the patient is a partner, should consist of in- and out-patient services, community care centres, self-help groups, family organizations, psychiatrists, psychologists, nurses, social workers, case managers, and GP's.

Our assessment of three pre-defined patient pathways (indicated prevention, reduction of untreated psychosis, relapse prevention) identified several critical barriers to optimal treatment.

\subsection{Indicated prevention: needs and treatment gaps}

Conspicuously, available health care services regularly miss or delay detection of symptoms and/or diagnosis. Current systems do not provide appropriate prevention for patients at risk and early detection services. Other contributing factors include lack of illness awareness among patients, families, and the public; lack of information, training and education among primary care providers; stigmatizing beliefs, prejudices and discriminating attitudes and actions towards schizophrenia patients.

From a biomedical perspective, selective schizophrenia prevention is not possible yet, since there are no reliable biomarkers or other measures for valid prediction of illness onset [25]. Identifying individuals at risk of illness could improve early diagnosis, initiate timely treatment, and ultimately contribute to the prevention of psychotic disorders [26]. So far, population atrisk states can be detected only insufficiently clinically and genetically (e.g., based on family history) [27]. Additional nonspecific environmental risk factors include prenatal infection or malnutrition, perinatal complications, season of birth, urbanicity, cannabis use, history of migration, etc [2].

More accessible preventive measures can be implemented in the population with manifest behavioral changes and nonspecific symptoms, such as odd thinking, social withdrawal, bizarre behavior, aggressiveness (i.e., indicated prevention). Effective prevention includes both early detection (identification of at-risk individuals, recognition of premorbid and prodromal changes) and early intervention (elimination of risk factors, preventive programs). The most typical periods for the onset of schizophrenia are late adolescence and early adulthood. Otherwise common displays of teens during puberty, adolescents, such as change of friends, 
Table 1

Patient and family member viewpoints.

\begin{tabular}{|c|c|}
\hline Phase of illness/ intervention & Needs and perspectives \\
\hline $\begin{array}{l}\text { Premorbid phase / preventive } \\
\text { measures }\end{array}$ & $\begin{array}{l}\text { - Increase awareness, knowledge and understanding of mental health problems. } \\
\text { - Promote healthy lifestyle at schools (social interaction, physical activity, etc.). } \\
\text { - Make psychological services at schools and universities readily accessible. } \\
\text { - Manage misuse of illicit substances. } \\
\text { - Reduce stigma, prejudice, and ignorance in relation to mental health problems and fight discrimination. } \\
\text { - Encourage individuals to seek a GP/psychiatrist/psychologist/counsellor when experiencing mental health problems; lowering the } \\
\text { threshold to attend primary care is crucial in the patient journey. } \\
\text { - Prevention should start before birth; education on risk factors prior to conception, during pregnancy and after childbirth is important. }\end{array}$ \\
\hline $\begin{array}{l}\text { Prodromal phase/ } \\
\text { early detection, } \\
\text { early intervention }\end{array}$ & $\begin{array}{l}\text { - Raise the awareness of prodromal symptoms among health professionals, teachers and other educators, trainers, police, etc. } \\
\text { - Psychological services at schools are crucial. } \\
\text { - Educate at-risk individuals and their caregivers; address their denial; inform them on the access to quality services. } \\
\text { - Support family organizations; establish a collaboration with mental health professionals. } \\
\text { - All professionals involved (health, educational, social, authorities) should communicate with each other, as well as with families. } \\
\text { - Develop apps monitoring subthreshold psychotic experiences and mood swings. } \\
\text { - Develop procedures for early diagnosis. } \\
\text { - Introduce clinically/biomedically based diagnosis. } \\
\text { - Implement early intervention: the earlier, the better [20]. } \\
\text { - Non-pharmacological (psychosocial) interventions can be effective for prodromal symptoms. }\end{array}$ \\
\hline $\begin{array}{l}\text { Acute episode / treatment } \\
\text { initiation }\end{array}$ & $\begin{array}{l}\text { - Initial contact should be with medical services rather than law authorities. } \\
\text { - Discuss the possible interventions covering relevant types of pharmacological and psychosocial treatments: objective information } \\
\text { tailored to the patient's needs is crucial (pros \& cons of interventions). } \\
\text { - Treatment should be personalized: the optimal mode for a specific patient should be selected. } \\
\text { - Open communication between mental health professionals and families is essential. } \\
\text { - Complex treatment requires therapeutic team that includes a psychiatrist, psychologist, social worker, case manager, family member. } \\
\text { - Home visits, mobile outreach services and crisis teams can step in during crisis, intervene timely and effectively, prevent } \\
\text { hospitalization. }\end{array}$ \\
\hline $\begin{array}{l}\text { Long-term phase / relapse } \\
\text { prevention }\end{array}$ & $\begin{array}{l}\text { - Patients want autonomy and participate in treatment decisions, including shared decision making on antipsychotic treatment. People } \\
\text { should have quality options to choose from, according to their needs. } \\
\text { - Patients do not want to be labeled as schizophrenic patients; they want to be treated as equal, with respect, to participate actively in } \\
\text { society, to study, have a family, keep a job, etc. } \\
\text { - Full/partial non-adherence poses a critical pitfall in the long-term management of schizophrenia [21]. } \\
\text { - Continuous pharmacological treatment controlling the symptoms significantly reduces the chance to relapse [22]. } \\
\text { - Managing suicidal risk can reduce mortality of schizophrenia patients [23]. } \\
\text { - Patients generally favor psychological treatments: psychotherapy, cognitive remediation, can target specific symptoms and needs. } \\
\text { - Patient and caregiver support groups, patients and family organizations, and peer programs can enhance autonomy and self- } \\
\text { management of illness. } \\
\text { - Customized psychosocial interventions, including social services, supported vocational services, supported housing, etc., play an } \\
\text { important role in the long-term management. } \\
\text { - Deinstitutionalization, community settings, case management are essential. }\end{array}$ \\
\hline Recovery & $\begin{array}{l}\text { - The control of symptoms is just a start, it is regarded as an important goal to reactivate the patient and restart his/her social activities. } \\
\text { - The role of therapeutic teams addressing all aspects of recovery is essential; there is a need for horizontal communication. Family } \\
\text { members should be integrated into care teams. } \\
\text { - Psychosocial interventions + involvement of caregivers in the treatment pathway are crucial steps for an independent, clinically } \\
\text { stable patient who is able to function. } \\
\text { - Emphasis should be put on physical health, which is integral part of well-being. } \\
\text { - Media campaigns may have just a short-term impact, the change of attitudes and style of reporting on mental health problems is } \\
\text { crucial. } \\
\text { - Prohibit explicitly discrimination on mental illness and provide support to patients that face discrimination. } \\
\text { - Create supportive, patient friendly workplaces without discrimination, with appropriate processes (return to work, case review) and } \\
\text { a proper management culture with occupational health and work safety strategies to support patients with mental illness. } \\
\text { - Respond to the changing needs along the process of ageing. }\end{array}$ \\
\hline
\end{tabular}

giving up hobbies, worsening of school or academic performance, sleep problems, mood swings, irritability, can also be first signs of imminent psychosis, and can therefore make diagnosis difficult. Indicated prevention has a potential to prevent a transition to psychotic disorder.

\subsubsection{Early detection}

First premorbid signs of psychosis include mild cognitive impairments, social deficits; prodromes manifest themselves as 'attenuated psychotic symptoms', or 'brief limited intermittent psychotic symptoms' $[28,29]$. Early detection and intervention may reduce the risk of conversion into fully blown illness [30]. Diagnosis of psychosis is based on observed behavior, subjective experiences, and reports from others who are familiar with the person [31]. Prodromal psychotic syndrome can be assessed using various measures (e.g., Structured interview for Prodromal syndromes, SIPS; Scale of Prodromal Symptoms, SOPS; At Risk Mental State, ARMS; Brief Limited Intermittent Psychotic Symptoms, BLIPS; Comprehensive Assessment of At-Risk Mental States; CAARMS) [32-34]. A combination of factors can predict schizophrenia in up to $80 \%$ of young teenagers who are at high risk of developing the illness. 
Table 2

Factors affecting patients' journey.

\begin{tabular}{|c|c|}
\hline Positive effects & Negative effects \\
\hline $\begin{array}{l}\text { A stable patient is able to function well in the society within a supportive } \\
\text { environment, with a various degree of independence }\end{array}$ & $\begin{array}{l}\text { Untreated psychosis is associated with refusal of antipsychotic treatment and delayed help, } \\
\text { ultimately leads to functional decline and poor prognosis }\end{array}$ \\
\hline $\begin{array}{l}\text { Full/partial insight into the illness helps patient to accept and adhere to } \\
\text { antipsychotic treatment }\end{array}$ & $\begin{array}{l}\text { Non-adherence to treatment results in repeated relapses with numerous negative } \\
\text { consequences (neurobiological changes of the brain, unfavorable course and outcome of illness, } \\
\text { poor future treatment response, negative socioeconomic impact on individuals and society, } \\
\text { including high direct and indirect health costs) }\end{array}$ \\
\hline $\begin{array}{l}\text { Strong therapeutic alliance (with mental health professionals, } \\
\text { caregivers) yields better treatment outcome. }\end{array}$ & $\begin{array}{l}\text { Psychotic episode might pose a risk to the patient itself and for the society (suicidal ideation; } \\
\text { aggressiveness, violence, victimization) }\end{array}$ \\
\hline $\begin{array}{l}\text { Active patient's participation in treatment decisions strengthens } \\
\text { adherence to treatment }\end{array}$ & \\
\hline
\end{tabular}

The first recognition of psychosis is frequently not made by healthcare professionals, but by family and teachers, in medical emergency services or police / criminal justice system. Thus, awareness campaigns need to train teachers, sport coaches, etc. how to identify young people at risk. High-risk adolescents might be screened for example on the presence of prodromal symptoms or the history of schizophrenia in first-degree relatives. If necessary, an intervention program that aims to improve stress resilience, suboptimal maturation of neuronal pathways, prevent or alleviate adverse environmental circumstances and insults, can be implemented [20].

The setting for prevention would be schools, universities, workplaces, primary care (GP offices), or local public health authorities. A campaign underscoring the importance of an early diagnosis and intervention should also target first-line health care professionals, nurses, GP's, so they can refer patients to psychiatrists. It should be noted, that while prevention is usually funded from a budget of a single sector, prevention-related cost savings are beneficial across sectors. This makes it more difficult to persuade a single stakeholder to invest into the prevention. Convincing more stakeholders to take a joint action and invest into prevention together is a lengthy process, which requires highly developed diplomatic and negotiating skills.

Studies showed that more than $20 \%$ of schizophrenia patients who experienced barriers to contact a doctor to treat their physical problems reported stigma and fear of disclosing their mental health problem to a GP [35]. Reduction of stigma associated with mental illness over time is feasible and may contribute to effective prevention [36]. Mental health awareness campaigns should use evidence-based strategies to eliminate or reduce stigma, this may subsequently also improve the early detection [37].

Media play an important role; thus, all campaigns should specifically address the negative image of mental illness and patients among general public. The term of 'schizophrenia' itself can be perceived negatively even by health professionals, other diagnoses are often given instead. Interestingly, some Asian countries (Japan, Korea) recently changed the term 'schizophrenia' into 'integration disorder' or 'attunement disorder', respectively, which subsequently reduced stigmatization and fostered acceptance of diagnosis [38].

\subsubsection{Early intervention}

Many of the affected individuals suffer considerably at early stage. Symptomatic treatment (psychosocial and/or pharmacological) is indicated at this stage, especially for those with a considerable degree of distress. Cognitive behavioral therapy (CBT) can reduce the risk of developing psychosis in those at high risk after a year and is recommended by the National Institute for Health and Care Excellence (NICE) [39,40]. Another preventive measure is to avoid psychoactive substances that have been associated with development of the disorder [41]. A number of interventions that have demonstrated efficacy in other conditions are beneficial in schizophrenia, as well (e.g., physical exercise) [42]. Preventive psychosocial interventions aim at stress reduction, educational campaigns inform about risks related to substance misuse, accessible and low-threshold services provide counseling, support, and safe social environment to interact with peers.

Early intervention programs are already available in numerous countries. There are positive long-term experience from Australia (Personal Assessment and Crisis Evaluation Clinic, PACE), United Kingdom (Outreach and Support in South London, OASIS), Denmark (OPUS Study) and others [43-45]. The UK has implemented clinical guidelines and quality guidelines for such services, and the baseline auditing report has been published [46]. It reveals a large disparity in the services available across the UK, with some NHS Trusts offering the entire spectrum appropriately and others very little. The same observation applies for a view across various countries. There are data supporting the effectiveness of early intervention programs aiming to prevent schizophrenia [47]. A meta-analysis of published studies suggested that it might be possible to delay or prevent transition to psychosis in individuals at high risk, using various (psychological, pharmacological, or nutritional) interventions, with the best evidence for CBT [39].

\subsection{Timely intervention for manifested psychosis: needs and treatment gaps}

Although the population screening process can be costly, early intervention services have been shown to yield significant savings in societal (health- and social-care, and productivity) costs through preventing hospitalizations, increasing employment rates and decreasing involvement with the criminal justice system $[48,49]$. Therefore, there is a need to move away from the classical model where doctors assume a passive role, sitting within the service facility, waiting for patients to "find" them.

The typical experience of family members of schizophrenia patients with the first service contact is not through prevention/ screening/early interventions; in almost all cases their journey started with a crisis. Emergency medical assistance is needed, often followed by a hospital admission. There is a strong consensus that broad availability of well-organized outpatient services, mobile outreach teams, or low-threshold units (e.g., 24/7 crisis centers) could prevent many crises, involuntary treatments, it could reduce harm. The first encounter and experience with psychiatric services and treatment may determine not only patient's attitude towards therapy, but also the future course and outcome of illness. Therefore, access to a psychiatric expert or unit should be improved. GP's should refer the individual earlier to a specialized team; if they believe that the patient manifests with psychotic symptoms, they should refer him/her to a psychiatrist. Touchpoints for early diagnosis would be family and teachers who can reach out to psychology/counseling services.

The period between the onset of psychosis and treatment initiation is critical. Duration of untreated psychosis (DUP) is defined 
as the time from the first manifestation of the first psychotic symptom emergence to initiation of adequate drug treatment [50]. DUP encompasses both extrinsic factors, such as the local legal provisions (i.e. requirement of dangerousness for involuntary treatment), accessibility to mental health services, and intrinsic, illness-related factors. Mean values of DUP range from 8 to 48 weeks, it is important to keep in mind that potential deterioration in schizophrenia occurs most aggressively in the first $2-3$ years.

The duration of untreated psychosis can serve as an indirect measure of the effectiveness of early detection strategies and also as a predictor of treatment outcome [51-53]. Length of DUP has been related to a poor treatment response, insufficient symptom control, prominent negative symptoms, and poor overall functional outcome (failure to achieve remission, decreased social functioning, lower quality of life) [50]. On the other hand, evidence of the impact of DUP on the brain structural abnormalities is not fully conclusive, mainly due to the methodological inconsistencies (e.g., small sample sizes), similarly as the equivocal effect on cognitive impairment.

Early recognition and diagnosis, plus early intervention, can thus reduce the burden of schizophrenia; minimizing of DUP improves overall outcome and prognosis. Timely treatment reduce the number and duration of hospitalizations over 1-2 years after a first episode of psychosis [54,55], although the impact is less clear over the longer course of illness [56,57].

\subsection{Long-term management and relapse prevention: needs and treatment gaps}

One of the principal goals in the long-term management is to prevent relapses, maintain remission, and achieve functional recovery. Optimal illness management can positively influence the whole patient journey, as the vicious circle (psychotic episode, social withdrawal, quitting job/school, functional impairment, suicidal ideations, etc.) can be broken. Ideal treatment is characterized by adequate utilization of both the pharmacological and psychosocial interventions. Patients should consult on a regular basis a specialized team, to discuss their needs, short-term and long-term goals, treatment plans. The role of a psychiatrist is to manage the treatment pathway of the patient. There is an important role of therapeutic guidelines, available evidence suggests that adherence to guidelines improves patient outcomes, in contrast to treatment as usual, driven by clinical judgment only $[58,59]$

Schizophrenia is typically a multi-episodic disorder. Each relapse can worsen the course and outcome of the illness, reduce treatment response, have a severe negative impact on patients, their carers, and the whole health and social system [8]. Therefore, relapse prevention is essential for the management of schizophrenia. Among the factors that contribute to relapse/recurrence of illness, drug discontinuation plays a prominent role. Not only complete withdrawal of medication is hazardous, but also intermittent treatment jeopardizes patient's well-being [22]. Continuous treatment has been shown to be paramount in the reduction of relapse risk; patients are able to stay relapse-free for a significantly longer period of time.

Various sources report the rate of $40-50 \%$ schizophrenia patients who are non-adherent; $50-55 \%$ of all hospitalizations can be attributed to non-adherence [60]. Adherence to antipsychotic medication can be improved by using long-acting injectable antipsychotics (LAI), also called "depot" [61]. The advantage of LAI in comparison with oral formulations was not apparent in randomized controlled trials, since these tend to exclude nonadherent patients, and also generally increase adherence $[62,63]$. True benefit of LAI has been shown in pragmatic naturalistic studies that enroll all 'real-life' patients, including those who are non-adherent, relapsing, non-cooperative, with comorbid physical conditions, with aggressive behavior $[64,65]$.
Non-pharmacological interventions include psychoeducation, problem-oriented therapy, management of symptoms with cognitive-behavioral therapy (CBT), social skills training, cognitive remediation, etc. Involvement of the caregivers is very important: they need to be provided with information about the illness, psychoeducation on the importance of treatment continuity, how to recognize early symptoms of a new episode. Electronic systems monitoring early warning signs of imminent relapse (using text messages, apps, actigraphs) can be also employed. Telemetric warning signs monitoring (e.g., ITAREPS program) may significantly reduce the risk of relapse and help in timely intervention [24,66]. Moreover, technology could be used to monitor stable patients. The follow-up of patients on regular basis (monthly, bi-monthly, or three-monthly) could be automatic: i.e. electronic reminders sent to the patient and caregivers with a text indicating that the patient has an appointment. If the patient does not show up, a member of the assertive outreach mobile team or the informal carer can visit the patient at home [67].

Although insight (self-awareness of illness) is a prerequisite for therapy adherence and self-management, it might not be easily achieved [68]. Self-awareness of illness is a concept used to describe patient's acknowledgement of his/her strengths and limitations, in particular the ability to understand the nature of impairment and recognize its implications. Patients may not believe they are ill and may deny the need for therapy or they may have such disorganized thinking that they cannot remember to take their daily doses. There is a range of interventions that facilitate the development or improvement of self-awareness. Generally, it is believed that an individualized approach to address impairments of self-awareness is necessary: it takes into account whether the impairment of self-awareness is neurological, psychological or environmental in origin [69].

People with schizophrenia can take an active role in managing their own condition. Once they learn basic facts about the illness and its treatment, they can make informed decisions about their care, including pharmacotherapy, actively participate in shared decision on treatment and drug choice [70]. If patients know how to watch for the early warning signs of relapse and how to make a plan to respond, they can learn how to prevent relapses. Patients can also develop and use coping skills to deal with persistent symptoms.

\subsection{Long-term management: towards recovery}

The prognosis of social and professional reintegration is negatively correlated with the number of episodes of illness. Longer duration of untreated psychosis, higher number of relapses make it more difficult to fully recover and recovery will take more time. Moreover, untreated illness is associated with substance abuse and increased risk of violent behavior. A major factor causing non-adherence to drug treatment, in addition to illness-related factors (lack of insight), is that patients are often not well informed on the medication side effects and/or how to manage them.

Symptoms and cognitive impairment disrupt the psychosocial functioning of schizophrenia patients and often result in social problems, e.g., difficulties in relationships, giving up hobbies, decline in academic and/or work performance with subsequent economic and social decline [71]. The onset of illness during adolescence or young adulthood prevents patients from completing their academic or vocational training, establishing age-appropriate social relationships, initiating family life. Throughout the course of illness, impairments in adaptive life skills are a major source of disability. Many patients have difficulty keeping a job or taking care of themselves; thus, they have to rely on others to assist them. Stigmatizing attitudes and beliefs about schizophrenia are widespread and may interfere with patients' willingness to discuss their 
problems and seek treatment. High unemployment rate, lower educational level and socioeconomic status compared to unaffected peers, with subsequent dependence on social welfare may also have a negative impact on real-life functioning. Moreover, schizophrenia is associated with poor physical health, premature death and suicide, prejudice (stigma) and discrimination in many facets of life [72,73].

On the other hand, if properly treated via integrated biopsychosocial approach (including optimal antipsychotic treatment combined with psychosocial interventions), people with schizophrenia can live a fulfilling life. Effective, low-dose, safe and continuous antipsychotic treatment might lead to a functional recovery [22]. In the long-term management, the availability of rehabilitation programs is limited.

Rehabilitation emphasizes social and vocational training to assist people with schizophrenia participate fully in their communities. Since the patients' professional and social life trajectories are compromised, they need to develop new skills to reintegrate. Rehabilitation programs include employment services, money management counseling, cognitive remediation, and social skills training. These non-pharmacological interventions play an important role in the long-term schizophrenia management, improving overall functioning. Work reintegration is a frequently expressed goal for patients. While some patients cannot pursue their professional activity, many continue to work or wish to do so. The ability to keep a job with adequate support often results in improved quality of life and minimizes the negative financial impact and the risk of social exclusion.

We can witness a shift from emphasis on symptom control, achieving and maintaining remission, to the functional recovery. This approach is supported by growing clinical evidence indicating that a certain degree of recovery is possible, despite the presence of residual symptoms, and that some people with schizophrenia actually may achieve full recovery [74].

There are different definitions of recovery, clinical and patientbased [75]. The clinical recovery accentuates remission and functional improvement. Remission is defined as a reduction/ absence of symptoms to the point that they do not interfere significantly with behaviour, using clinical rating scales [76,77]. Functional improvement implies the ability to function in the community, socially and vocationally living independently, having friends, etc. The patient-based definition of recovery has been developed based on personal experiences of people with mental illness [75]. The most frequently used definition is: "the development of new meaning and purpose in one's life, as one grows beyond the catastrophic effects of mental illness." [78] Recovery from schizophrenia is a highly individual process. The four key processes of personal recovery are finding hope, re-establishment of identity, finding meaning in life, and taking responsibility for recovery. In other words: connectedness, hope, identity, meaning, and empowerment (the acronym "CHIME") [79,80].

Box 1. Opportunities for improvement in the management of schizophrenia.

- Fight stigma, raise awareness, target public opinion, policy makers, other medical professionals (including GP's), media.

- Be inspired and learn from available experiences and existing preventive programs.

- Promote psychoeducation.

- Develop network of outpatient and community services; improve access to social services.

- Provide individual case management to address specific patient's needs.

- Make non-pharmacological therapeutic options available (CBT, cognitive remediation ....).

- Utilize new drug formulations (e.g., long-acting injectable, LAI).

- Employ IT technologies in monitoring early warning signs and relapse prevention.

- Use real-life (effectiveness) outcome measures beyond symptom control: subjective well-being, satisfaction with medication, quality of life, functional recovery.

- Focus on somatic health of patients, improve their physical well-being.

- Reduce burden of comorbidities (e.g., substance abuse).

- Engage patients in treatment decisions.

- Support active involvement of families and families organizations

Box 2. Policy recommendations.

- Promote and facilitate efficient health services organization: develop integrated community care and the cooperation of caregivers, social workers, nurses, psychologists, specialists, families, and peers.

- Improve economic aspects (cost-effectiveness) of the systems: promote early detection programs and utilize most already available treatments.

- Consider evidence-based resource allocations, support neuroscience research.

- Governmental financial incentives are needed to create the optimal environment to succeed

- Shift policy recommendations from reducing high costs of brain disorders to modification of health systems. Close the gap between public policies and practice.

- Raise awareness of general public and other medical professionals; fight stigma. Support volunteers empowered by professionals and responsible authorities.

- Support patients and groups of caregivers for information, expertise, sharing experiences, and advocacy.

- Facilitate the establishment of active partnerships and cooperation with other stakeholders, e.g. the media organizations (local, regional, national, European and academic institutions), employers and trade unions, pharmaceutical industry, governments, regulatory bodies and insurers with a goal to

o secure the best possible treatment for patients with a mental illness and at the earliest possible opportunity

o support the development of health/mental health policies which take into account patients' perspective 
Recovery is not mere absence of symptoms, but a journey through which the person may achieve a meaningful life. Attaining an improved quality of life, physical health, social integration, instrumental competence and self-agency, independent living, and competitive employment can be seen as elements of a meaningful life, and therefore pursued to a variable degree, depending on the person and the context.

Our analysis of the patient journey showed that the current model of care does not provide optimal management of schizophrenia due to the poor collaboration among health and social care professionals and lack of continuity of the antipsychotic treatment. Furthermore, there is insufficient cooperation between care providers and patients and their families, plus inadequate utilization of pharmacological and psychosocial interventions, and proper patient monitoring. There is still low implementation of deinstitutionalization across many, especially Central and Eastern European countries [81]. Taking patients out of the hospitals, back to their own environments, has been demonstrated to be beneficial to the patients while not leading to severe adverse consequences [82-84]. By deinstitutionalization, we mean a careful and responsible shift in the locus of care from psychiatric hospitals to communities, i.e. strongly supporting community care and families while making a transition and reducing the number of beds in long-term psychiatric wards.

The reviewed data suggested a significant overlap between patient/family and professional perspectives - trust amongst them being the foundation for successful management throughout the illness course [85]. Opportunities for further improvement of care provided by the mental health professionals can be seen in various areas, as summarized in the Box 1.

The results of our analysis have also significant policy implications. Based on the available evidence and users' needs, further supported by the economic data, we can sum up general policy recommendations addressed to the policymakers and respective authorities (Box 2).

\section{Conclusions}

Most people with schizophrenia need a lifelong treatment; however, they can live their own life if they receive timely and proper treatment. In general, we found that the provision of early detection and early intervention programs is of great importance for an effective management of the illness. Optimal management requires a paradigm shift in the focus of schizophrenia treatment, from mere symptom control, achieving and maintaining remission, to the emphasis on recovery. Economic arguments supporting this call are provided in the accompanying report [18]. Changing the paradigm demands challenging adaptations of health and social care, moving away from fragmentation to a seamless care model. For this purpose, effective mental health policies are needed.

\section{Funding}

This work on schizophrenia is part of a series of case studies covering nine neurological and psychiatric conditions, conducted within the "Value of Treatment for Brain Disorders" research project of the European Brain Council. PM and PW were supported by the Ministry of Education, Youth and Sports of the Czech Republic (project NPU4NUDZ: LO1611); PM was supported by the Ministry of Health of the Czech Republic (grant No. AZV 15-28998A).

\section{Declarations of interest}

None.

\section{References}

[1] Owen M.J., Sawa A, Mortensen PB. Schizophrenia. Lancet 2016;388 (10039):86-97.

[2] Tandon R, Keshavan MS, Nasrallah HA. Schizophrenia, "just the facts" what we know in 2008. 2. Epidemiology and etiology. Schizophr Res 2008;102:1-18.

[3] Jin H, Mosweu I. The societal cost of schizophrenia: a systematic review. Pharmacoeconomics 2017;35:25-42.

[4] Walker ER, McGee RE, Druss BG. Mortality in mental disorders and global disease burden implications: a systematic review and meta-analysis. JAMA Psychiatry 2015;72:334-41.

[5] Tandon R, Nasrallah HA, Keshavan MS. Schizophrenia, "just the facts" 4. Clinical features and conceptualization. Schizophr Res 2009;110:1-23.

[6] Hor K, Taylor M. Suicide and schizophrenia: a systematic review of rates and risk factors. J Psychopharmacol 2010;24(4 Suppl):81-90.

[7] Emsley R, Chiliza B, Asmal L, Harvey BH. The nature of relapse in schizophrenia. BMC Psychiatry 2013;13:50.

[8] Emsley R, Chiliza B, Asmal L. The evidence for illness progression after relapse in schizophrenia. Schizophr Res 2013;148:117-21.

[9] Harrison G, Hopper K, Craig T, Laska E, Siegel C, Wanderling J, et al. Recovery from psychotic illness: a 15- and 25-year international follow-up study. $\mathrm{Br} \mathrm{J}$ Psychiatry 2001;178:506-17.

[10] Lang FU, Kösters M, Lang S, Becker T, Jäger M. Psychopathological long-term outcome of schizophrenia-a review. Acta Psychiatr Scand 2013:127:173-82.

[11] Kotov R, Fochtmann L, Li K, Tanenberg-Karant M, Constantino EA, Rubinstein J, et al. Declining clinical course of psychotic disorders over the two decades following first hospitalization: evidence from the Suffolk county mental health project. Am J Psychiatry 2017; 174:1064-74.

[12] Jääskeläinen E, Juola P, Hirvonen N, McGrath JJ, Saha S, Isohanni M, et al. A systematic review and meta-analysis of recovery in schizophrenia. Schizophr Bull 2013;39:1296-306.

[13] Lora A, Kohn R, Levav I, McBain R, Morris J, Saxena S. Service availability and utilization and treatment gap for schizophrenic disorders: a survey in 50 low- and middle-income countries. Bull World Health Organ 2012;90:47-54 54A-54B.

[14] Andlin-Sobocki P, Jönsson B, Wittchen HU, Olesen J. Cost of disorders of the brain in Europe. Eur J Neurol 2005;12(Suppl 1):1-27.

[15] Gustavsson A, Svensson M, Jacobi F, Allgulander C, Alonso J, Beghi E, et al. Cost of disorders of the brain in Europe 2010. Eur Neuropsychopharmacol 2011;21:718-79.

[16] EBC Research Project - The Value of Treatment for brain disorders: Policy White Paper, http://www.braincouncil.eu/wp-content/uploads/2017/06/ EBC_white_policy_paper_DEF26072017_Low.pdf [Accessed 14.01.2018].

[17] Schrijvers G, van Hoorn A, Huiskes N. The care pathway: concepts and theories: an introduction. Int J Integr Care 2012;12:e192 (Spec Ed Integrated Care Pathways)

[18] Winkler P, Broulikova HM, Kondratova L, Knapp M, Arteel P, Boyer P, et al Decision modelling for developing early detection and early intervention services in the Czech Republic Manuscript, submitted. 2018.

[19] Larsen TK, Friis S, Haahr U, Joa I, Johannessen JO, Melle I, et al. Early detection and intervention in first-episode schizophrenia: a critical review. Acta Psychiatr Scand 2001;103:323-34.

[20] Sommer IE, Bearden CE, van Dellen E, Breetvelt EJ, Duijff SN, et al. Early interventions in risk groups for schizophrenia: what are we waiting for? NPJ Schizophr 2016;2:16003.

[21] King D, Knapp M, Patel A, Amaddeo F, Tansella M, Schene A, et al. The impact of non-adherence to medication in patients with schizophrenia on health, social care and societal costs. Analysis of the QUATRO study. Epidemiol Psychiatr Sci 2014;23:61-70.

[22] De Hert M, Sermon J, Geerts P, Vansteelandt K, Peuskens J, et al. The use of continuous treatment versus placebo or intermittent treatment strategies in stabilized patients with schizophrenia: a systematic review and meta-analysis of randomized controlled trials with first- and second- generation antipsychotics. CNS Drugs 2015;29:637-58.

[23] Nordentoft M, Mortensen PB, Pedersen CB. Absolute risk of suicide after first hospital contact in mental disorder. Arch Gen Psychiatry 2011;68:1058-64.

[24] Spaniel F, Vohlídka P, Hrdlicka J, Kozený J, Novák T, Motlová L, et al. ITAREPS: information technology aided relapse prevention programme in schizophrenia. Schizophr Res 2008;98:312-7.

[25] Cannon TD, Cornblatt B, McGorry P. The empirical status of the ultra high-risk (prodromal) research paradigm. Schizophr Bull 2007;33:661-4.

[26] Tandon N, Shah J, Keshavan MS, Tandon R. Attenuated psychosis and the schizophrenia prodrome: current status of risk identification and psychosis prevention. Neuropsychiatry (London) 2012;2:345-53.

[27] Smieskova R, Marmy J, Schmidt A, Bendfeldt K, Riecher-Rössler A, Walter M, et al. Do subjects at clinical high risk for psychosis differ from those with a genetic high risk? A systematic review of structural and functional brain abnormalities. Curr Med Chem 2013;20:467-81.

[28] Fusar-Poli P, Cappucciati M, Borgwardt S, Woods SW, Addington J, Nelson B, et al. Heterogeneity of psychosis risk within individuals at clinical high risk: a meta-analytical stratification. JAMA Psychiatry 2016;73:113-20.

[29] Schultze-Lutter F, Michel C, Schmidt SJ, Schimmelmann BG, Maric NP, Salokangas RK, et al. EPA guidance on the early detection of clinical high risk states of psychoses. Eur Psychiatry 2015;30:405-16. 
[30] Larsen TK, Melle I, Auestad B, Haahr U, Joa I, Johannessen JO, et al. Early detection of psychosis: positive effects on 5-year outcome. Psychol Med 2011;41:1461-9.

[31] American Psychiatric Association. Diagnostic and statistical manual of mental disorders. 5th ed. Arlington, VA: American Psychiatric Publishing; 2013.

[32] Fusar-Poli P, Cappucciati M, Rutigliano G, Lee TY, Beverly Q, Bonoldi I, et al. Towards a standard psychometric diagnostic interview for subjects at ultra high risk of psychosis: CAARMS versus SIPS. Psychiatry J 2016;2016:7146341.

[33] Fusar-Poli P, Rutigliano G, Stahl D, Davies C, De Micheli A, et al. Long-term validity of the at risk mental state (ARMS) for predicting psychotic and nonpsychotic mental disorders. Eur Psychiatry 2017:42:49-54.

[34] Fusar-Poli P, Cappucciati M, De Micheli A, Rutigliano G, Bonoldi I, et al. Diagnostic and prognostic significance of brief limited intermittent psychotic symptoms (BLIPS) in individuals at ultra high risk. Schizophr Bull 2017;43: 48-56.

[35] Brohan E, Elgie R, Sartorius N, Thornicroft G; GAMIAN-Europe Study Group. Self-stigma, empowerment and perceived discrimination among people with schizophrenia in 14 European countries: the GAMIAN-Europe study. Schizophr Res 2010;122:232-8.

[36] Angermeyer MC, Matschinger H, Carta MG, Schomerus G. Changes in the perception of mental illness stigma in Germany over the last two decades. Eur Psychiatry 2014;29:390-5.

[37] Thornicroft G, Mehta N, Clement S, Evans-Lacko S, Doherty M, et al. Evidence for effective interventions to reduce mental-health-related stigma and discrimination. Lancet 2016;387(10023):1123-32.

[38] Sartorius N, Chiu H, Heok KE, Lee MS, Ouyang WC, Sato M, et al. Name change for schizophrenia. Schizophr Bull 2014;40:255-8.

[39] Stafford MR, Jackson H, Mayo-Wilson E, Morrison AP, Kendall T. Early interventions to prevent psychosis: systematic review and meta-analysis. BMJ 2013;346:f185.

[40] National Collaborating Centre for Mental Health (UK). Psychosis and schizophrenia in adults: treatment and management: updated edition 2014 London: National Institute for Health and Care Excellence (UK); 2014.

[41] Picchioni MM, Murray RM. Schizophrenia. BMJ 2007;335(7610):91-5.

[42] Rosenbaum S, Tiedemann A, Sherrington C, Curtis J, Ward PB. Physical activity interventions for people with mental illness: a systematic review and metaanalysis. J Clin Psychiatry 2014;75:964-74.

[43] Yung AR, Yuen HP, McGorry PD, Phillips LJ, Kelly D, Dell’Olio M, et al. Mapping the onset of psychosis: the comprehensive assessment of at-risk mental States. Aust NZ J Psychiatry 2005;39:964-71.

[44] Outreach and Support OASIS, http://www.slam.nhs.uk/oasis [Accessed 14.01.2018].

[45] Albert N, Melau M, Jensen H, Emborg C, Jepsen JR, Fagerlund B, et al. Five years of specialised early intervention versus two years of specialised early intervention followed by three years of standard treatment for patients with a first episode psychosis: randomised, superiority, parallel group trial in Denmark (OPUS II). BMJ 2017;356:i6681.

[46] Healthcare Quality Improvement Partnership and the Royal College of Psychiatrists. Report of the Early Intervention in Psychosis. Publication number: CCQI237, https://www.rcpsych.ac.uk/PDF/EIP\%20Audit\%20Report\% 20FINAL.pdf [Accessed 14.01.2018].

[47] Marshall M, Rathbone J. Early intervention for psychosis. Cochrane Database Syst Rev 2011(6) CD004718.

[48] Park AL, McCrone P, Knapp M. Early intervention for first-episode psychosis: broadening the scope of economic estimates. Early Interv Psychiatry 2016;10:144-51.

[49] Andrew A, Knapp M, McCrone P, Parsonage M, Trachtenberg M. Effective interventions in schizophrenia: the economic case. London: Personal Social Services Research Unit, London School of Economics and Political Science; 2012

[50] Murru A, Carpiniello B. Duration of untreated illness as a key to early intervention in schizophrenia: a review. Neurosci Lett 2016 pii: S0304-3940 (16)30745-5.

[51] Marshall M, Lewis S, Lockwood A, Drake R, Jones P, Croudace T. Association between duration of untreated psychosis and outcome in cohorts of firstepisode patients: a systematic review. Arch Gen Psychiatry 2005;62:975-83.

[52] Perkins DO, Gu H, Boteva K, Lieberman JA. Relationship between duration of untreated psychosis and outcome in first-episode schizophrenia: a critical review and meta-analysis. Am J Psychiatry 2005;162:1785-804.

[53] Penttilä M, Jääskeläinen E, Hirvonen N, Isohanni M, Miettunen J. Duration of untreated psychosis as predictor of long-term outcome in schizophrenia: systematic review and meta-analysis. Br J Psychiatry 2014;205:88-94.

[54] Petersen L, Jeppesen P, Thorup A, Abel MB, Øhlenschlaeger J, Christensen TØ, et al. A randomised multicentre trial of integrated versus standard treatmen for patients with a first episode of psychotic illness. BMJ 2005;331(7517):602.

[55] Craig TK, Garety P, Power P, Rahaman N, Colbert S, Fornells-Ambrojo M, et al. The Lambeth early onset (LEO) team: randomised controlled trial of the effectiveness of specialised care for early psychosis. BMJ 2004;329(7474):1067.

[56] The schizophrenia commission. The abandoned illness: a report from the schizophrenia commission. London: Rethink Mental Illness; 2012.

[57] Gafoor R, Nitsch D, McCrone P, Craig TK, Garety PA, Power P, et al. Effect of early intervention on 5-year outcome in non-affective psychosis. Br J Psychiatry 2010;196:372-6.

[58] Howes OD, Vergunst F, Gee S, McGuire P, Kapur S, Taylor D. Adherence to treatment guidelines in clinical practice: study of antipsychotic treatment prior to clozapine initiation. Br J Psychiatry 2012;201:481-5.
[59] Bighelli I, Ostuzzi G, Girlanda F, Cipriani A, Becker T, Koesters M, et al. Implementation of treatment guidelines for specialist mental health care. Cochrane Database Syst Rev 2016;12:CD009780.

[60] García S, Martínez-Cengotitabengoa M, López-Zurbano S, Zorrilla I, López P, Vieta E, et al. Adherence to antipsychotic medication in bipolar disorder and schizophrenic patients: a systematic review. J Clin Psychopharmacol 2016;36:355-71.

[61] Haddad PM, Brain C, Scott J. Nonadherence with antipsychotic medication in schizophrenia: challenges and management strategies. Patient Relat Outcome Meas 2014;5:43-62.

[62] Leucht C, Heres S, Kane JM, Kissling W, Davis JM, Leucht S. Oral versus depot antipsychotic drugs for schizophrenia-a critical systematic review and metaanalysis of randomised long-term trials. Schizophr Res 2011;127:83-92.

[63] Kane JM, Kishimoto T, Correll CU. Assessing the comparative effectiveness of long-acting injectable vs. Oral antipsychotic medications in the prevention of relapse provides a case study in comparative effectiveness research in psychiatry. J Clin Epidemiol 2013;66:S37-41.

[64] Kirson NY, Weiden PJ, Yermakov S, Huang W, Samuelson T, Offord SJ, et al. Efficacy and effectiveness of depot versus oral antipsychotics in schizophrenia: synthesizing results across different research designs. J Clin Psychiatry 2013;74:568-75

[65] Mohr P, Knytl P, Voráčková V, Bravermanová A, Melicher T. Long-acting injectable antipsychotics for prevention and management of violent behaviour in psychotic patients. Int J Clin Pract 2017;71(9).

[66] Komatsu H, Sekine Y, Okamura N, Kanahara N, Okita K, Matsubara S, et al. Effectiveness of information technology aided relapse prevention programme in schizophrenia excluding the effect of user adherence: a randomized controlled trial. Schizophr Res 2013;150(1):240-4.

[67] Van Loon H, Peuskens J, Dubois V, Gillain B, Vanderboelle H, Geerts P. Les taux de rechutes et les couts de soins asserifs ajoutes aux antipsychotiques de longue durée: une étude de type cohort appariá? [Relapse rates and cost of adding assertive outreach to long-acting antipsychotic treatment in schizophrenia: a matched cohort study]. Acta Psych Belgica 2016;116:39-48.

[68] Forbes VJ. Unawareness as a barrier to treatment in patients with schizophrenia: a conceptual analysis. J Psychosoc Nurs Ment Health Serv 2010;48:30-6.

[69] Fleming J, Ownsworth T. A review of awareness interventions in brain injury rehabilitation. Neuropsychol Rehabil 2006;16:474-500.

[70] Morrison AP, Hutton P, Shiers D, Turkington D. Antipsychotics: is it time to introduce patient choice? Br J Psychiatry 2012;201:83-4

[71] Galderisi S, Rossi A, Rocca P, Bertolino A, Mucci A, Bucci P, et al. The influence of illness-related variables, personal resources and context-related factors on real-life functioning of people with schizophrenia. World Psychiatry 2014; $13: 275-87$.

[72] Corrigan PW, Watson AC. Understanding the impact of stigma on people with mental illness. World Psychiatry 2002:1:16-20.

[73] Fleischhacker WW, Arango C, Arteel P, Barnes TR, Carpenter W, Duckworth K, et al. Schizophrenia-time to commit to policy change. Schizophr Bull 2014;40 (Suppl 3):S165-94.

[74] Warner R. Recovery from schizophrenia and the recovery model. Curr Opin Psychiatry 2009;22:374-80.

[75] Van Eck RM, Burger TJ, Vellinga A, Schirmbeck F, de Haan L. The relationship between clinical and personal recovery in patients with schizophrenia spectrum disorders: a systematic review and meta-analysis. Schizophr Bull 2017, doi:http://dx.doi.org/10.1093/schbul/sbx088.

[76] Liberman RP, Kopelowicz A, Ventura J, Gutkind D. Operational criteria and factors related to recovery from schizophrenia. Int Rev Psychiatry 2002; $14: 256-72$

[77] Andreasen NC, Carpenter WT, Jr, Kane JM, Lasser RA, Marder SR, et al. Remission in schizophrenia:proposed criteria and rationale for consensus. Am J Psychiatry 2005;162:441-9.

[78] Anthony WA. Recovery from mental illness: the guiding vision of the mental health service system in the 1990s. Psychosoc Rehabil J 1993;16:11-23.

[79] Andresen R, Oades L, Caputi P. The experience of recovery from schizophrenia: towards an empirically validated stage model. Aust N Z J Psychiatry 2003;37:586-94.

[80] Leamy M, Bird V, Le Boutillier C, Williams J, Slade M. Conceptual framework for personal recovery in mental health: systematic review and narrative synthesis. Br J Psychiatry 2011;199:445-52.

[81] Winkler P, Krupchanka D, Roberts T, Kondratova L, Machů V, Höschl C, et al. A blind spot on the global mental health map: a scoping review of 25 years' development of mental health care for people with severe mental illnesses in central and eastern Europe. Lancet Psychiat 2017;4:634-42.

[82] Kunitoh N. From hospital to the community: the influence of deinstitutionalization on discharged long-stay psychiatric patients. Psychiatry Clin Neurosci 2013;67:384-96.

[83] Knapp M, Beecham J, McDaid D, Matosevic T, Smith M. The economic consequences of deinstitutionalisation of mental health services: lessons from a systematic review of European experience. Health Soc Care Commun 2011;19:113-25.

[84] Winkler P, Barrett B, McCrone P, Csémy L, Janoušková M, Höschl C. Deinstitutionalised patients, homelessness and imprisonment: systematic review. Br J Psychiatry 2016;208:421-8.

[85] Gaebel W, Muijen M, Baumann AE, Bhugra D, Wassermann D, et al. EPA guidance on building trust in mental health services. Eur Psychiatry 2014;29:83-100. 